\title{
Assessment and Evaluation of the Leaf Extract of Begonia barbata to the Reduction LDL-Cholesterol in Carbamazepine Induced Obese Rats
}

\author{
Md. Ashiqur Rahamn ${ }^{1 *}$, Sifat Ara ${ }^{2}$, Mohammed Kyokobad Hosain ${ }^{3}$, and Bushra Rahman² \\ ${ }^{1}$ Department of pharmacy, ASA University Bangladesh, Dhaka, Bangladesh; ${ }^{2}$ Department of Pharmaceutical Sciences, North \\ South University, Dhaka, Bangladesh; and ${ }^{3}$ Dept. of Forensic Medicine and Toxicology, Gonoshasthaya Samaj Vittik \\ Medical College, Savar, Dhaka, Bangladesh.
}

*Correspondence: 7upmilon@gmail.com

\begin{abstract}
Scientific endeavor has made it possible to discover and synthesize lipid lowering drugs but, in most of the cases, their beneficial effects are overshadowed by their adverse effects. Hence, research interest on screening of medicinal plants has intensified in recent years with a view of discovering potential antioxidants, lipid and glucose lowering phytochemicals. Four month feeding of carbamazepine (both $5 \mathrm{mg} / \mathrm{kg}$ and $20 \mathrm{mg} / \mathrm{kg}$ body weight) with normal diet increased the body mass of rats. Low density lipoprotein (LDL) cholesterol level was increased based on the oral execution of carbamazepine. But high density lipoprotein (HDL) cholesterol level and weight of liver increased slightly and the level of triacylglycerol (TG) and total cholesterol (TC) level remain unchanged. Nonetheless, the Begonia barbata feeding with normal diet reduced the carbamazepine induced obesity at both high and low doses. The level of LDL cholesterol and liver weight was significantly decreased due to the oral execution of B. barbata together with normal diet and carbamazepine, where HDL level was changed but not significantly.
\end{abstract}

Keywords: Assessment, Begonia barbata, Leaf extract, LDL-Cholesterol, Obese Rats, HDL, and Carbamazepine.

\section{INTRODUCTION:}

Obesity is most commonly caused by a combination of excessive food intake, lack of physical activity and genetic susceptibility (Yazdi et al., 2015). Obesity progresses towards metabolic syndrome which is defined by a constellation of interconnected physiological, biochemical and clinical factors including dyslipidemia, hypertension, and diabetes, pro inflammatory and pro thrombotic state. These conditions are directly linked to higher level of LDL cholesterol, lower level of HDL cholesterol, oxidative stress and elevated blood glucose. On average, obese person have higher energy expenditure than their normal counterparts due to the energy needed to maintain a raised body mass UniversePG I www.universepg.com
(Kushner, 2007). Obesity results from an imbalance of food intake, basal metabolism, and energy expenditure. At an individual level, multiple endogenous or environmental causes could lead to obesity (Flier, 2014). However, in most cases, a coalescence of excess energy intake and availability of energy-dense meals is thought to be the main contributor to obesity (Wisse and Kim, 2007).

In the past 20-30 years, there have been many studies characterizing the responses of animals exposed to high-fat diets (Zhang, 2010). In the mice, the $\mathrm{A} / \mathrm{J}$ mouse and $\mathrm{C} 57 \mathrm{BL} / \mathrm{KsJ}$ mouse are relatively resistant to high-fat diet when compared to $\mathrm{C} 57 \mathrm{BL} / 6 \mathrm{~J}$ mouse (Rossmeis, 2005). The B6 mouse is a distinctly better 
model mimicking human metabolic insanity that are showed in obesity because when fed ad libitum with a high-fat foods, these mice progress obesity, hyperinsulinemia, hyper-glycemia, and hyper-tension, but when fed ad libitum to chow diet, they remain lean without metabolic abnormalities (Collins and Martin, 2004). The high-fat diets effects on blood glucose level are more contrary and based on the type of nutritive regimen. Hyperglycemia usually develops within 4 weeks of a high-fat diet (Sato, 2010).

Inhibition of Akt and mTOR pathway by rapamycin has effects in longevity (Cox and Mattison, 2009; Firoz et al., 2016), adipocyte differentiation, and obesity (Chang, 2009). Recent studies have shown that S6K1-deficient mice and Akt1 knockout mice exhibit are prevented from diet-induced obesity through model of murine high-fat diet induced obesity described below (Um, 2004). While a specific amount of fat is required for normal physiological functioning (Powers and Howley, 2001), obesity and overweight are correlated with numerous health problems, viz heart diseases, diabetes, stock, hyper-lipidemia, osteo-porosis, gout, cancer and osteoarthritis (Corbin et al., 2002; Akinpelu and Akinola, 2009; Gbiri et al., 2010). It is used in schizophrenia along with other medications and as a second-line agent in bipolar disorder (The American Society of Health-System Pharmacists, 2015). Carbamazepine shows to functioning as well as phenytoin and valproate (Nolan et al., 2017). There is few argument concerning the teratogenic effects of carbamazepine, but maximum of scientists believe that malformations associated with maternal usage of can carbamazepine be frequently cleaved into key malformations viz craniofacial defects, heart defects, and neural tube defects and minor anomalies such as growth retardation, developmental delay, and hyperplasia of the nails or distal phalanges (Jallon and Picard, 2001).

This interaction has been demonstrated through hypothalamic-mediated mechanisms in rat models with epilepsy (St-Pierre et al., 2009), amygdala-mediated mechanisms in kindled rats (Hum et al., 2009), and hippocampus and fornix-mediated mechanisms in rats (Davidson et al., 2009; Sharif et al., 2019) and humans (Metzler-Baddeley et al., 2013). One of those drugs, vigabatrin, is normally better tolerated than the older compounds, but has recently been shown to be more frequently associated with weight gain than carbamazepine (Chadwick, 2003). However, they are not recommended for usage due to the toxicity associated with them (Patel et al., 2013). Plants synthesize several antioxidants to them against damage caused by active, reactive oxygen species (ROS) ( $\mathrm{Rad}$ and Sen, 2013; Rad and Mohsenzadeh, 2014).

These compounds include chlorophyll derivatives, alkaloids, essential oils, phytosterols, phenolics and polyphenolics ( $\operatorname{Rad}$ and Alfatemi, 2001). Some of the antioxidants that have been isolated from plants include curcumin, eugenol, flavonoids, coumarins, carotenoids, tannins, gallic acid, limonene, terpenoids, $\beta$-sitosteroletc (Sha-rifi et al., 2014; Gupta and Sharma, 2006). Tubers of this plant are found to be rich in starch, mucilage, sugar, phosphate, chloride and a glucoside-loroglossin (Pant and Rinchen, 2011; Sarkar et al., 2015). The gum resin comprising of mainly $\beta$-boswellic acids along with 11-keto- $\beta$ boswellic acids and their ace-tates has been focused to have anti-bacterial activity (Raja and Ali, 2011). The gum resin has been reported to have a definite role in the treatment of rheumatoid arthritis and boswellic acid has been manifested as most potent inhibitor of 5lipoxygenase, a key enzyme involved in inflammation (Siddiquedi et al., 2011). Anti-bacterial activity against gram-positive bacteria like $S$. aureus, B. subtilis and all gram-negative bact-eria have been demonstrated in a recent study (Singh and Khajuria 2007; Das 2012; Mosaib et al., 2020).

Numerous clinical studies performed in hyperlipidemic subjects have manifested a beneficial effect of RYR extract supplements (Bogsrud and Ose, 2010) resulting in a decrease in plasma total cholesterol (TC), LDL-C and triacylglycerols (TG). In some cases, an increase of high-density-lipoprotein cholesterol (HDL-C) was also demonstrated (Liu and Zhang, 2006). Depending on the Monascusstrains use and the conditions of fermentation, they may hold in polyketides called monacolins (Heber and Lembertas, 2001). A data review and a meta-analysis also revealed a more favorable action of policosanols on serum lipids compared with phyto-sterols and stanols, and an equivalent effect to statins (Chen and Wesley, 2005; Gouni-Berthold and Bert-hold, 2002). Oxidized LDL-cholesterol 
(Wider and Pittler, 2009; Toshima et al., 2000). It has been shown that men and women supplemented with daily doses exceeding $100 \mathrm{IU}$ of vitamin $\mathrm{E}$ for over 2 years showed a significant reduction in heart attacks (Bowen and Borthakur, 2004).

In the recent meta-analysis that indicated a TG-lowering effect of plant stanols (Naumann et al., 2008; Rony et al., 2019), significant interaction was observed between baseline TG concentrations and plant stanol intake, resulting in larger TG reductions (showed in $\mathrm{mmol} / \mathrm{L}$ ) with more baseline $\mathrm{TG}$ concentrations. As HDL-C metabolism is closely related to that of TG via the action of the cholesterol-ester transfer protein (CETP) (Chap-man and Le, 2010) the effect of PSenriched food consumption on HDL-C concentrations was also evaluated. In the Air Force/Texas Coronary Atherosclerosis Prevention Study (AFCAPS/TexCAPS), treatment with lovastatin resulted in a $6 \%$ mean increase in HDL-cholesterol (Gotto and Boccuzzi, 2000). Healthy diet and physical exercise have bene-ficial effects on the improvement of the serum lipid profile, with reduction of total cholesterol (TC), TG, and LDL-C with increase of HDL-C (Chapman, 2004; Kelly, 2010; Uddin et al., 2016). The mixed controlling role of these two food models has been defined as "Mediterr Asian diet" (Nicklas and O'Neil, 2014; Pallauf and Giller, 2013). In two recent works (Laing et al., (2000) manifested that the quantum growth of photosystem II (PSII) and the oxidation state of PSII (qP) decrease as PPFD increases, while electron transport ratio and non-photo-chemical quenching enlarge. The aim of this work was to examine the ability of carbamazepine to induce obesity and related dyslipidemia in female Wister rats. And subsequently to evaluate ability of $B$. barbata leaf ext-ract to reduce carbamazepine induced weight gain and dyslipidemia (Shahen et al., 2019; Habib et al., 2019; Talukder et al., 2020).

\section{MATERIALS AND METHODS:}

Animal - The whole study protocol to carry out several experiments related to this project will be approved by Ethical Committee of Dept. of Pharmaceutical Sciences, North South University (NSU), Bangladesh, for animal care and experimentation. For investigating the effect of each leaf extract, 30 days old rats (for UniversePG I www.universepg.com each group) having similar body weight will be obtained from animal production unit of Dept. of Pharmaceutical Sciences, North South University, and will be housed at room temperature of $22 \pm 3^{\circ} \mathrm{C}$, humidity of $55 \%$, in $12 \mathrm{~h}$ dark/light cycles with standard laboratory chow diet and drinking water ad libitum (Khatun et al., 2016). The animal's usage in this experiment was Wistar rat (Rattus norvegicus) approved by Dept. of Pharmaceutical Sciences, NSU. There were 25 female normal Wistar rats used \& age was 30 days. The animals housed were under controlled environment room $22-25^{\circ} \mathrm{C}$ and humidity (50\%) and a 12/12 h dark/light cycle.

Experiment design - Wistar rats were kept in animal house under room temperature and divided in 5 groups. Each group contains 5 rates. Different type of food is given to the different group and observed their body weight, liver weight and cholesterol level.

Group-1: Normal diet

Group-2: Normal diet + Carbamazepine low dose (5 $\mathrm{mg} / \mathrm{kg}$ ) orally everyday

Group-3: Normal diet + Carbamazepine high dose (20 $\mathrm{mg} / \mathrm{kg}$ ) orally everyday

Group-4: Normal diet + Carbamazepine high dose (5 $\mathrm{mg} / \mathrm{kg})+$ B. barbata $(10 \mathrm{mg} / \mathrm{kg})$ orally everyday

Group-5: Normal diet + Carbamazepine high dose (20 $\mathrm{mg} / \mathrm{kg})+$ B. barbata $(10 \mathrm{mg} / \mathrm{kg})$ orally everyday

Blood sample collection - Rats were anesthetized with ketamine $(100 \mathrm{mg} / \mathrm{kg}$ body weight, $0.1 \mathrm{ml})$ before sacrificing. Then blood was collected from aorta and heart. Then the blood was transferred to the Eppendorf tube and the blood was centrifuged at $10,000 \mathrm{rpm}$ keeping temperature at $4^{0} \mathrm{C}$ for 10 minutes to separate the blood cells as pellet. Finally serum was collected carefully by micropipette. The liver collected carefully by opening the abdominal cavity and wet weight was measured by electronic balance.

Measurement of body weight of rats - The body weight was taken daily when rats were 4 weeks old and was continued up to 20 weeks and this body weight was taken by electronic balance.

Measurement of HDL cholesterol value of rats HDL Cholesterol LS test - Phosphotungstic acid and magnesium ions fastidious precipitating all lipoproteins without the HDL fraction - cholesterol 
present in the supernatant can be determined by the same method used for total cholesterol. The reactions are as follows:

1) ApoB containing lipoproteins $+\alpha$-cyclodextrin + $\mathrm{Mg}+2+$ dextran $\mathrm{SO}_{4}--->$ soluble non-reactive com-plexes with apoB-containing lipoproteins

2) HDL-cholesteryl esters PEG-cholesteryl esterase $>$ HDL-unesterified cholesterol + fatty acid

3) Unesterifiedchol $+\mathrm{O}_{2}$ PEG-cholesterol oxidase $>$ cholestenone $+\mathrm{H}_{2} \mathrm{O}_{2}$

4) $\mathrm{H}_{2} \mathrm{O}_{2}+5$-aminophenazone $+\mathrm{N}$-ethyl-N-(3-methylphenyl)-N'_succinyl ethylene diamine $+\mathrm{H}_{2} \mathrm{O}+$ $\mathrm{H}+$ Peroxidase $>$ qunoneimine dye $+\mathrm{H}_{2} \mathrm{O}$

\section{Reagents}

R1

Precipitating reagent - Phosphotungstic acid Magnesium chloride $0.02 \mathrm{~mol} / \mathrm{L} 1 \mathrm{~mol} / \mathrm{L} 2$

Determination of HDL-Cholesterol
R2

Standard cholesterol $50 \mathrm{mg} / \mathrm{dL}(1.29 \mathrm{mmol} / \mathrm{L})$

Additional Reagent - Cholesterol Kit

Stability - The reagents are stable up to the expiry date specified when stored at +4 to $+8{ }^{\circ} \mathrm{C}$.

Samples: Fresh serum. Heparin or EDTA plasma may be used. Sample should not be frozen. HDL-Cholesterol is stable up to 5 days at +4 to $+8^{\circ} \mathrm{C}$.

\section{Procedure}

Sample $0.20 \mathrm{ml}$

Precipitating reagent (R1) $0.02 \mathrm{ml}$

Vortex, let stand $10 \mathrm{~min}$., centrifuge for $15 \mathrm{~min}$. at $3000 \mathrm{rpm}$. Measure HDL-Cholesterol in the supernatant was using the same method for total Cholesterol.

\begin{tabular}{|l|l|l|l|}
\hline & Blank $(\mathbf{m l})$ & Standard $(\mathbf{m l})$ & Sample $(\mathbf{m l})$ \\
\hline Distilled water & 0.05 & $\ldots \ldots \ldots \ldots \ldots$ & $\ldots \ldots \ldots \ldots$ \\
\hline Standard (R2) & $\ldots \ldots \ldots \ldots$ & 0.05 & $\ldots \ldots \ldots \ldots$ \\
\hline Supernatant & $\ldots \ldots \ldots . . . \ldots \ldots \ldots$ & 0.05 \\
\hline Working reagent & 1.00 & $\ldots \ldots \ldots \ldots$ & 1.00 \\
\hline
\end{tabular}

Mix, incubate at $37^{\circ} \mathrm{C}$ for $10 \mathrm{~min}$. Read absorbance of

SODIUM CITRATE $\quad 0.064 \mathrm{~mol} / 1$ STABILIZERS $\quad 2 \%$

R2

Standard cholesterol $50 \mathrm{mg} / \mathrm{dL}(1.29 \mathrm{mmol} / \mathrm{L})$

\section{Procedure}

Each cholesterol standard and sample should be evaluated in duplicate or triplicate. A newly prepared standard curve should be utilized each time the assay is performed. Assay Protocol

a) Add $50 \mu \mathrm{L}$ of the diluted cholesterol standards or the diluted HDL fraction samples to the 96well microtiter plate.

b) Add $50 \mu \mathrm{L}$ of the pursued Cholesterol Reaction to each well and mix the well contents thoroughly.

c) Cover the plate wells to save the reaction from heat. Incubate the plate for 45 minutes at $37^{\circ} \mathrm{C}$.

d) IMMEDIATELY count the plate with a fluorescence microplate counter equipped for exci-

R1

Precipitating reagent - HEPARIN0.68g/1 
tation in the $530-570 \mathrm{~nm}$ order and for emission in the 590-600 $\mathrm{nm}$ order.

e) Determine the concentration of cholesterol within samples by differentiating the sample RFU to the cholesterol standard bow.

\begin{tabular}{lccc} 
Blank $(\mathrm{ml})$ & \multicolumn{2}{c}{ Standard $(\mathrm{ml})$} & Sample $(\mathrm{ml})$ \\
Distilled water & & ---- & ----- \\
Standard (R2) & ----- & $100 \mathrm{ul}$ & ----- \\
Supernatant & ----- & ------ & $100 \mathrm{ul}$ \\
Working reagent $1000 \mathrm{ul}$ & $1000 \mathrm{ul}$ & $1000 \mathrm{ul}$
\end{tabular}

Mix, incubate at $37^{\circ} \mathrm{C}$ for $10 \mathrm{~min}$. Read absorbance of sample (A Sample) and standard (A Standard) against the blank at $490 \mathrm{~nm}$.

Quality Control - For accuracy and reproducibility control: - Assayed Multi - Sera, Normal and Elevated.

\section{Measurement of TG value of rats}

Triglycerides - Triglycerides are measured enzymatically in serum or plasma using a series of coupled reactions in which TG is hydrolyzed to yield glycerol. Glycerol is then oxidized utilizing glycerol oxidase and $\mathrm{H}_{2} \mathrm{O}_{2}$ one of the reaction goods, is measured as described above for cholesterol. Absorbance is measured at $500 \mathrm{~nm}$. The reaction sequence is as follows:

Lipase

Triglycerides $+3 \mathrm{H}_{2}$

O -----------> glycerol + fatty acids

glycerokinase

Glycerol + ATP ------> glycerol-3-phosphate + ADP

glycerophosphate oxidase

Glycerol-3-phosphate $+\mathrm{O}_{2}$----->dihydroxyacetone phosphate $+\mathrm{H}_{2} \mathrm{O}_{2}$

Peroxidase $\mathrm{H}_{2} \mathrm{O}_{2}+$ 4-aminophenazone + 4-chlorophenol -----> 4-(p-benzoquinone-monoimino) phenazone $+2 \mathrm{H}_{2} \mathrm{O}+\mathrm{HCl}$

\section{Reagent}

R1

Precipitating reagent - p-chlorophenole $2 \mathrm{~mol} / \mathrm{L}$; lipoprotein lipase $150000 \mathrm{u} / 1$

glycerol-3-p-oxidase $800 \mathrm{u} / 1$; peroxidase $4000 \mathrm{u} / 1$

4-aminoantipyrine $440 \mathrm{u} / 1$; ATP $0.7 \mathrm{mmol} / 1$

Pipes buffer, $\mathrm{pH} 7.20 .7 \mathrm{mmol} / 1 ; 0.7 \mathrm{mmol} / 150 \mathrm{mmol} / 1$

R2

Glycerol equivalent to a concentration of $200 \mathrm{mg} / \mathrm{dl}$ $(2.28 \mathrm{mmol} / \mathrm{l})$ triglyceride $200 \mathrm{mg} / \mathrm{dl}$
Samples: Serum, heperanised plasma

\section{Procedure}

1) Add $50 \mu \mathrm{L}$ of the triglyceride samples to the 96well microtiter plate.

2) Add $50 \mu \mathrm{L}$ of the prepared triglyceride Reaction to each well and mix the well contents thoroughly.

3) Cover the plate wells to save the reaction from heat. Incubate the plate for 45 minutes at $37^{\circ} \mathrm{C}$.

4) IMMEDIATELY count the plate with a fluorescence microplate count equipped for excitation in the 530-570 $\mathrm{nm}$ order and for emission in the 590-600 nm order.

5) Examine the concentration of cholesterol within the samples by differentiating the sample RFU to the cholesterol standard bow.

$\begin{array}{lccc}\text { Blank (ml) } & & \text { Standard (ml) } & \text { Sample (ml) } \\ \text { Distilled water } & & ---- & ----- \\ \text { Standard (R2) } & ------- & 10 \mathrm{ul} & ----- \\ \text { Supernatant } & ------ & ----- & 10 \mathrm{ul} \\ \text { Working reagent } 1000 \mathrm{ul} & 1000 \mathrm{ul} & 1000 \mathrm{ul}\end{array}$

Mix, incubate at $37^{\circ} \mathrm{C}$ for $10 \mathrm{~min}$. Read absorbance of sample (A Sample) and standard (A Standard) against the blank at $490 \mathrm{~nm}$.

Quality Control - For accuracy and reproducibility control: - Assayed Multi - Sera, Normal and Elevated.

\section{Measurement of TC level of rats}

Total Cholesterol - Cholesterol is measured enzymaticcally in serum or plasma in a series of coupled reactions that hydrolyze cholesteryl esters and oxidize the 3-OH group of cholesterol. One of the reaction byproducts, $\mathrm{H}_{2} \mathrm{O}_{2}$ is counted quantitatively in a peroxidase catalyzed reaction that yields a color. Absorbance is measured at $500 \mathrm{~nm}$. The color intensity is proportional to cholesterol concentration. The reaction chronology is as follows:

Cholesteryl ester hydrolase

Cholesteryl ester + - $\mathrm{H}_{2} \mathrm{O}$----> cholesterol + fatty acid cholesterol oxidase

Cholesterol $+\mathrm{O}_{2}$----> cholest-4-en-3-one $+\mathrm{H}_{2} \mathrm{O}_{2}$ Peroxidase

$2 \mathrm{H}_{2} \mathrm{O}_{2}$ 4-aminophenazone + phenol ----> 4-(p-benzoquinonemonoimino)-phenazone $+4 \mathrm{H}_{2} \mathrm{O}$ 


\section{Reagent concentration}

R1

Precipitating reagent - Pipes buffer, $\mathrm{pH} 6.990 \mathrm{mmol} / \mathrm{L}$

Phenol 26mmol / L; Cholesterol oxidase 200u/1

Cholesterol esterase 300u/l; Peroxidase 1250u/1

4-aminoantipyrine. $4 \mathrm{mmol} / 1$

R2

Standard cholesterol $200 \mathrm{mg} / \mathrm{dL}(5.17 \mathrm{mmol} / \mathrm{L})$

Samples: Serum, plasma collected on heparin

\section{Procedure}

Each cholesterol standard and sample should be examined in duplicate or triplicate. A newly prepared standard bow should be utilized each time the assay is performed. Assay Protocol -

a) Add $50 \mu \mathrm{L}$ of the diluted cholesterol standards or the diluted HDL snippet samples to the 96well microtiter plate.

b) Add $50 \mu \mathrm{L}$ of the prepared Cholesterol Reaction to each well, and mix the well contents thoroughly.

c) Cover the plate wells to save the reaction from heat. Incubate the plate for 45 minutes at $37^{\circ} \mathrm{C}$.

d) IMMEDIATELY count the plate with a fluorescence microplate count equipped for excitation in the 530-570 $\mathrm{nm}$ order and for emission in the 590-600 nm order.

Initial Wt

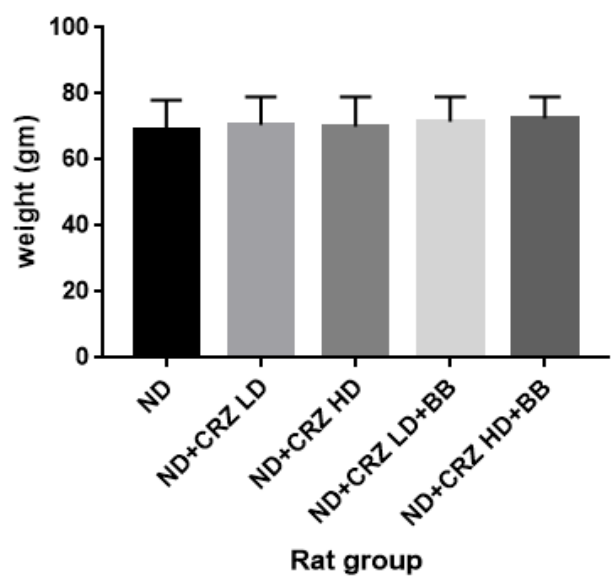

( A ) e) Dertermine the concentration of cholesterol within samples by differentiating the sample RFU to the cholesterol standard bow.

Blank (ml) Standard (ml) Sample (ml)

Distilled water

Standard (R2) ------- 10ul

Supernatant ----- ------ 10ul

Working reagent $1000 \mathrm{ul} 1000 \mathrm{ul} 1000 \mathrm{ul}$

Mix, incubate at $37^{\circ} \mathrm{C}$ for $10 \mathrm{~min}$. Read absorbance of sample (A Sample) and standard (A Standard) against the blank at $490 \mathrm{~nm},(490 \mathrm{~nm})$.

Measurement of liver weight of rats - After sacrificing the rat liver weight was taken and liver weight was taken by electronic balance.

\section{RESULTS AND DISCUSSION:}

Carbamazepine (CRZ) able to increase weight Simultaneously $B$. barbata leaf extract was given to other two groups of rats which were also fed with low dose (ND+CRZLD+BB) and high dose (ND+CRZLD+BB) of carbamazepine daily with normal diet. Feeding of carbamazepine and $B$. barbata started when rats were 4 weeks old and was continued up to 20 weeks.

Final WT

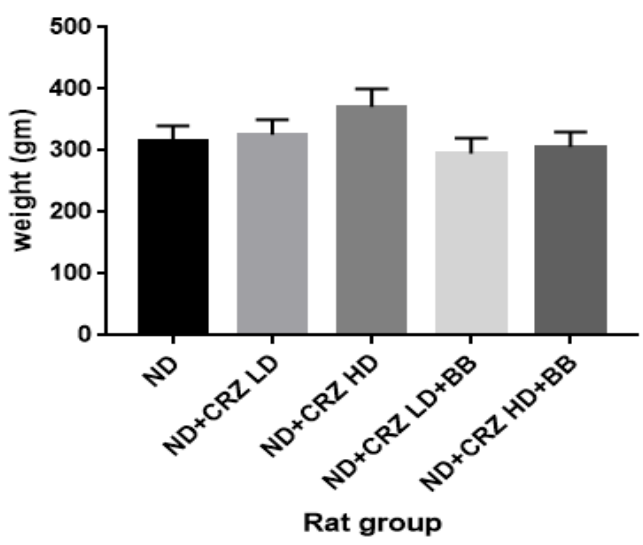

( B )

Fig 1: Feeding of rats with normal diet (ND), carbamazepine in low dose (ND+CRZLD) and carbamazepine in high dose (ND+CRZLD) with normal diet. Body weights were measured every week by electronic balance and initial (A); and final (B) body weights of different groups of rats are represented in the bar diagram. 


\section{B. barbata able to increase HDL}

In group 1 we can see HDL value is normal due to intake of normal food. Small amount of CBZ (5mg/ $\mathrm{kg}$ ) decrease the HDL value shown in group 2. And large amount of CRZ $(20 \mathrm{mg} / \mathrm{kg})$ decrease more HDL value shown in group 3. In case of small amount of $\mathrm{BB}(5 \mathrm{mg} / \mathrm{kg}) \mathrm{HDL}$ value is increasing that is shown in group 4. Finally large amount of bb $(20 \mathrm{mg} / \mathrm{kg})$ increase the HDL value most that is shown in group 5 .

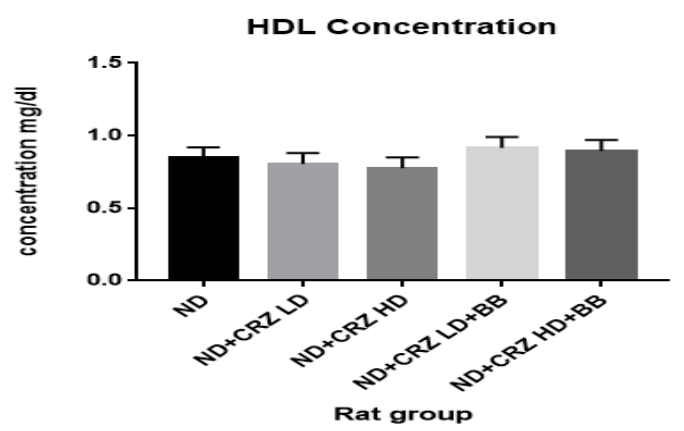

Fig 2: Feeding of rats with normal diet (ND), carbamazepine in low dose (ND+CRZLD) and carbamazepine in high dose (ND+CRZLD) with normal diet.

Simultaneously B. barbata leaf extract was given to other two groups of rats which were also fed with low dose (ND+CRZLD+BB) and high dose (ND+CRZLD $+B B)$ of carbamazepine daily with normal diet (Fig 2). Feeding of carbamazepine and B. barbata started when rats were 4 weeks old and was continued up to 20 weeks. HDL cholesterol was measured of different groups of rats are represented in the bar diagram (Alam et al., 2015).

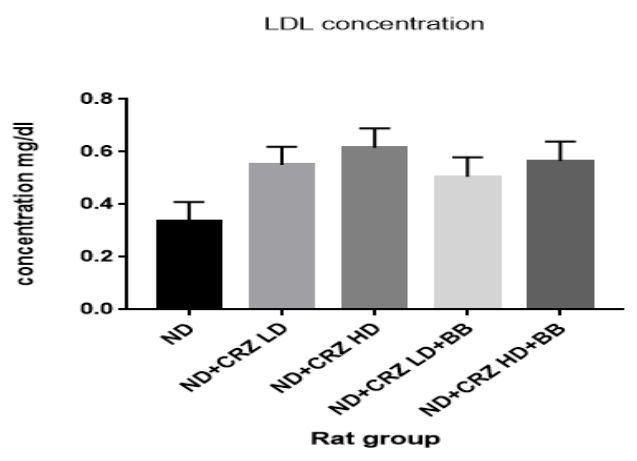

Fig 3: Feeding of rats with normal diet (ND), carbamazepine in low dose (ND+CRZLD) and carbamazepine in high dose (ND+CRZLD) with normal diet.

\section{B. barbata able to decrease LDL}

In this graph we can see different amount of CRZ $(5 \mathrm{mg} / \mathrm{kg}$ and $20 \mathrm{mg} / \mathrm{kg})$ increase the LDL value as followed by group 2 and 3. And different amount of BB $(5 \mathrm{mg} / \mathrm{kg}$ and $20 \mathrm{mg} / \mathrm{kg})$ is decreasing the value of LDL that is shown in group 4 and 5.

Simultaneously $B$. barbata leaf extract was given to other two groups of rats which were also fed with low dose (ND+CRZLD+BB) and high dose (ND+CRZLD+BB) of carbamazepine daily with normal diet. Feeding of carbamazepine and B. barbata started when rats were 4 weeks old and was continued up to 20 weeks. LDL cholesterol was measured of different groups of rats are represented in the bar diagram (Fig 3).

\section{B. barbata able to decrease Triglyceride level}

In this graph we can see different amount of CRZ $(5 \mathrm{mg} / \mathrm{kg}$ and $20 \mathrm{mg} / \mathrm{kg})$ increase the $\mathrm{TG}$ value as followed by group 2 and 3. And different amount of BB $(5 \mathrm{mg} / \mathrm{kg}$ and $20 \mathrm{mg} / \mathrm{kg})$ is decreasing the value of TG that is shown in group 4 and 5.

TG Concentration

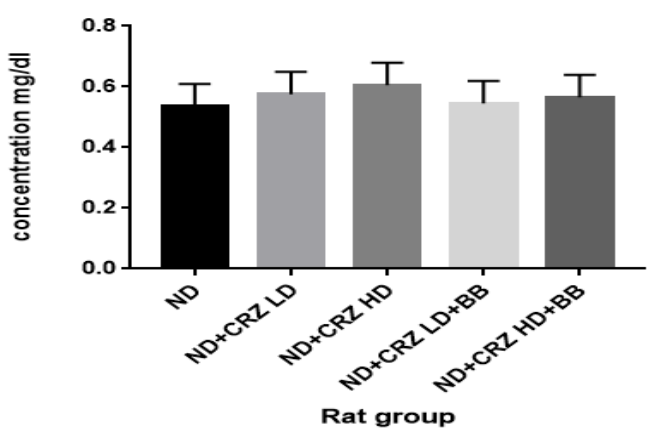

Fig 4: Feeding of rats with normal diet (ND), carbamazepine in low dose (ND+CRZLD) and carbamazepine in high dose (ND+CRZLD) with normal diet.

Simultaneously B. barbata leaf extract was given to other two groups of rats which were also fed with low dose (ND+CRZLD+BB) and high dose (ND+CRZL$\mathrm{D}+\mathrm{BB})$ of carbamazepine daily with normal diet. Feeding of carbamazepine and B. barbata started when rats were 4 weeks old and was continued up to 20 weeks. TG cholesterol was measured of different groups of rats are represented in the bar diagram (Fig 4). 


\section{B. barbata able to reduce Total cholesterol}

In this graph we can see different amount of CRZ $(5 \mathrm{mg} / \mathrm{kg}$ and $20 \mathrm{mg} / \mathrm{kg})$ increase the $\mathrm{TC}$ value as followed by group 2 and 3 . And different amount of BB $(5 \mathrm{mg} / \mathrm{kg}$ and $20 \mathrm{mg} / \mathrm{kg})$ is decreasing the value of TC that is shown in group 4 and 5.

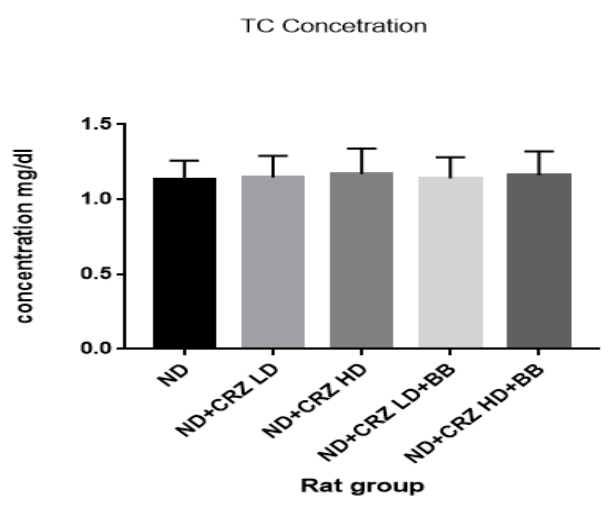

Fig 5: Feeding of rats with normal diet (ND), carbamazepine in low dose (ND+CRZLD) and carbamazepine in high dose (ND+CRZLD) with normal diet.

Simultaneously B. barbata leaf extract was given to other two groups of rats which were also fed with low dose (ND+CRZLD+BB) and high dose (ND+CRZLD+BB) of carbamazepine daily with normal diet (Fig 5). Feeding of carbamazepine and $B$. barbata started when rats were 4 weeks old and was continued up to 20 weeks. Total cholesterol was measured of different groups of rats are represented in the bar diagram.

\section{B. barbata able to reduce Liver weight}

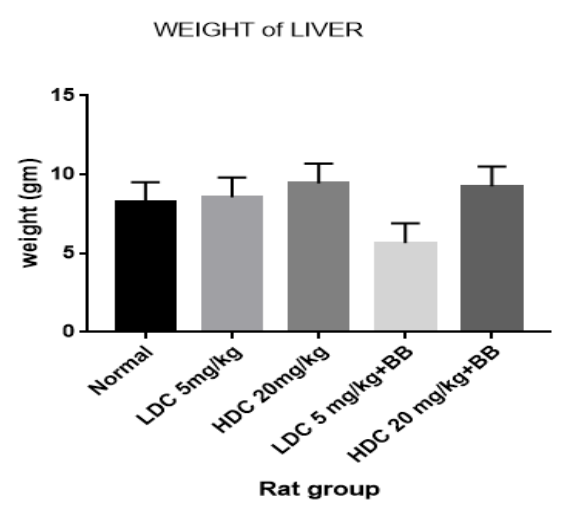

Fig 6: Feeding of rats with normal diet (ND), carbamazepine in low dose (ND+CRZLD) and carbamazepine in high dose (ND+CRZLD) with normal diet.
Simultaneously $B$. barbata leaf extract was given to other two groups of rats which were also fed with low dose (ND+CRZLD+BB) and high dose (ND+CRZLD+BB) of carbamazepine daily with normal diet. Feeding of carbamazepine and $B$. barbata started when rats were 4 weeks old and was continued up to 20 weeks. Liver weight was measured of different groups of rats are represented in the bar diagram (Fig 6).

\section{CONCLUSION:}

Carbamazepine (CRZ) intake is increasing obesity and weight gain of rats. This is the side effect of this drug. Carbamazepine increased appetite deposition of fat in body. On the other hand apply the leaf extract of $B$. barbata is decreasing that weight of rates. This plant extract can reduce cholesterol. In this study we observed B. barbata can reduce TG, LDL, TC and can increase the LDL value which are good for our health and this plant extract can be play a great role to control weight.

\section{ACKNOWLEDGEMENT:}

I would first like to thank our study team for providing the profound gratitude to my family and friends for providing me with constant inspiration and unfailing support to conduct this research work.

\section{CONFLICTS OF INTEREST:}

The author's declared there are no potential conflicts of the interest.

\section{REFERENECES:}

1) Akinpelu AO, Akinola TO, Gbiri CA. (2009). Adiposity indices and health status of urban dwellers in Lagos, Nigeria. International J. of Nutrition Education and Obesity 41: 347-352. https://pubmed.ncbi.nlm.nih.gov/19717118/

2) Alam MF, Amin R, Uddin ME, Biswas SK, and Islam MM. (2015). Regeneration of shoot from nodal explants of Cucumis sativus considering different hormonal concentration. Intern. Res. J. of Biol. Sci., 4(7): 1-5. http://www.isca.in/IJBS/Archive/v4/i7/10.ISCAIRJBS-2015-083.pdf

3) Baigent C, Keech A, Kearney PM, Simes R. (2005). Efficacy and safety of cholesterollowering treatment: prospective meta-analysis 
of data from 90,056 participants in 14 randomised trials of statins. Lancet 366:12671278.

4) Bogsrud MP, Ose L, Langslet G, Retterstol K. (2010). HypoCol (red yeast rice) lowers plasma cholesterol: a randomized placebo controlled study. ScandCardiovasc J 44:197-200. https://pubmed.ncbi.nlm.nih.gov/20636227/

5) Bowen PE, Borthakur G (2004) Postprandial lipid oxidation and cardiovascular disease risk. CurrAtheroscler Rep 6:477-484.

6) Chadwick D. (2003). Safety and efficacy of vigabatrin and carbamazepine in newly diagnosed epilepsy: a multicentreran domised double-blind study. Vigabatrin Europe 2003.

7) Chang GR et al. (2009). Rapamycin protects against high fat diet-induced obesity in C57BL/6J mice. J Pharmacol Sci.109: 496-503.

8) Chapman M. J. (2004). Are the effects of statins on HDL-cholesterol clinically relevant? Europ. Heart J. Supplements. 6: C58-C63. https://doi.org/10.1016/j.ehjsup.2004.04.002

9) Chapman MJ, Le GW, Guerin M, Kontush A. (2010). Cholesteryl ester transfer protein: at the heart of the action of lipid-modulating therapy with statins, fibrates, niacin, and cholesteryl ester transfer protein inhibitors. Eur Heart J. 31:149-164.

10) Chen JT, Wesley R, Shamburek RD, Pucino F, Csako G. (2005). Meta-analysis of natural therapies for hyperlipidemia: plant sterols and stanols versus policosanol. Pharmacotherapy 25:171-183.

https://pubmed.ncbi.nlm.nih.gov/15767233/

11) Collins S, Martin TL, Surwit RS, Robidoux J. (2004). Genetic vulnerability to diet-induced obesity in the C57BL/6J mouse: physiological and molecular characteristics. PhysiolBehav. 81: 243-248.

12) Corbin CB, Lindsey R, Welk G. (2002). Concepts of physical fitness: Active Lifestyle for Wellness. $10^{\text {th }}$ ed, Boston, McGraw-Hill. https://www.amazon.com/Concepts-PhysicalFitness-Lifestyles-Wellness/dp/0078022576

13) Cox LS, Mattison JA. (2009). Increasing longevity through caloric restriction or rapamycin feeding in mammals: common mechanisms for common outcomes? Aging Cell. 8: 607613.

14) Daniels ZS, Nick TG, Liu C, Glauser TA. (2009). Obesity is a common comorbidity for pediatric patients with untreated, newly diagnosed epilepsy. Neurology 73: 658-64.

https://pubmed.ncbi.nlm.nih.gov/19474413/

15) Das S. (2012). Antimicrobial activity study of ethanolic extract of Boerha aviadiffusa whole plant. Int J Pharm Life Sci. 3(10): 2006-2009.

16) Davidson TL, Chan K, Jarrard LE, Benoit SC. (2009). Contributions of the hippocampus and medial prefrontal cortex to energy and body weight regulation. Hippocampus 19: 235-52. https://pubmed.ncbi.nlm.nih.gov/18831000/

17) Firoz, M.A., Uddin ME., and Khatun, M.M. (2016). Studies on the effect of various sterilization procedures for in vitro seed germination and successful micropropagation of Cucumis sativus. International J. of Pure \& Applied Bioscience, 4(1): 75-81, https://doi.org/10.18782/2320-7051.2226

18) Flier JS. (2004). Obesity wars: molecular progress confronts an expanding epidemic. Cell. 116: 337-350.

19) Gbiri CA, Akinpelu AO, Odole AC. (2010). Prevalence, Pattern and Impact of Depression on Quality of Life of Stroke Survivors. Int J Psychiatry ClinPract 14: 198-203. https://doi.org/10.3109/13651501003797633

20) Gotto A. M., Boccuzzi S. J., Cook J. R., et al. (2000). Effect of lovastatin on cardiovascular resource utilization and costs in the Air Force/ Texas Coronary Atherosclerosis Prevention Study (AFCAPS/TexCAPS). AFCAPS/Tex CAPS Research Group. American Journal of Cardiology. 86: 1176-1181.

21) Gouni-Berthold I, Berthold HK. (2002). Policosanol: clinical pharmacology and therapeutic significance of a new lipid-lowering agent. Am Heart J 143: 356-365.

https://pubmed.ncbi.nlm.nih.gov/11835043/

22) Gupta VK and Sharma SK. (2006). Plants as natural antioxidants. Natural Product Radiance, 5(4): 326-334.

23) Habib MA, Akter S, Hannan MA. (2019). Evaluation of neuropharmacological activities 
of methanolic extract of B. monnieri in mice model. Eur. J. Med. Health Sci., 1(6), 41-49. https://doi.org/10.34104/ejmhs.01941049

24) Haw C, Bailey S. (2001). Body mass index and obesity in adolescents in a psychiatric medium secure. J Hum Nutr Diet.

25) Heber D, Lembertas A, Lu QY, Bowerman S, Go VL. (2001). An analysis of nine proprietary Chinese red yeast rice dietary supplements: implications of variability in chemical profile and contents. J Altern Complement Med 7: 133-139.

https://pubmed.ncbi.nlm.nih.gov/11327519/

26) Huang CF, Li TC, Shih HC, Lai MM. (2007). Efficacy of Monascus purpureus Went rice on lowering lipid ratios in hypercholesterolemic patients. Eur J CardiovascPrevRehabil 14: 438-440.

27) Hum KM, Megna S, Burnham WM. (2009). Lack of laterality in the effects of right and left amygdala kindling on weight gain in female rats. Epilepsy Res 87: 40-6. https://pubmed.ncbi.nlm.nih.gov/19720500/

28) Jallon P, Picard F. (2001). Bodyweight gain and anticonvulsants: a comparative review. Drug Saf 24: 969-978.

29) Kelly R. B. (2010). Diet and exercise in the management of hyperlipidemia. American Family Physician. 81(9): 1097-1102. https://pubmed.ncbi.nlm.nih.gov/20433126/

30) Khatun M. M., Abdur. M. Razzak, Firoz Alam M, Ekhlas Uddin M, and Yesmin S. (2016). Standardization of In Vitro sterilization procedures for micropropagation of ginger (Zingiber officinale Rosc.), Intern. J. of Appl. Biol. and Pharma. Technol., 7(1): 131-137. http://www.ijabpt.com/pdf/32012-M.\%20M.\% 20Khatun.pdf

31) Kurzthaler I, Fleischacker WW. (2001). The clinical implications of weight gain in schizophrenia. J Clin Psychiatry 62: 32-37.

32) Lin CC, Li TC, Lai MM. (2005). Efficacy and safety of $M$. purpureus Went rice in subjects with hyperlipidemia. Eur $J$ Endocrinol 153: 679-686.

33) Liu J, Zhang J, Shi Y, Fonnebo V. (2006). Chinese red yeast rice (M. purpureus) for primary hyperlipidemia: a meta-analysis of randomized controlled trials. Chin Med 1: 4.

https://doi.org/10.1186/1749-8546-1-4

34) Metzler-Baddeley C, Baddeley RJ, Jones DK, O’Sullivan MJ. (2013). Indivi-dual differences in fornix microstructure and body mass index. PLoS One 8: e59849.

35) Mosaib MG, Islam R, Mahmud S. (2020). Antibacterial activity of Cissus quadrangularis stem extract on the pathogenic and industrial waste watered bacteria. Eur. J. Med. Health Sci., 2(2), 28-38.

https://doi.org/10.34104/ejmhs.020.28038

36) Naumann E, Plat J, Kesler AD, Mensink RP. (2008). The baseline serum lipoprotein profile is related to plant stanol induced changes in serum lipoprotein cholesterol and triacylglycerol concentrations. J Am CollNutr. 27: 117126.

37) Nevitt, SJ; Marson, AG; Tudur, C. (2017). Carbamazepine versus phenytoin monotherapy for epilepsy: an individual participant data review". The Cochrane Database of Systematic Reviews. 2: CD001911.

https://doi.org/10.1002/14651858.CD001911pub3

38) Nicklas T. A., O'Neil C. E., Fulgoni V. L. (2014). Rice consumption is associated with better nutrient intake and diet quality in adults: National Health and Nutrition Examination survey (NHANES) 2005-2010. Food and Nutrition Sciences. 5: 525-532.

39) Nolan, SJ; Marson, AG; Tudur Smith, C. (2016). "Phenytoin versus valproate monotherapy for partial onset seizures and generalised onset tonic-clonic seizures: an individual participant data review". The Cochrane Database of System. Reviews. 4: CD00-1769. https://doi.org/10.1002/14651858.CD001769.pub3

40) Pallauf K., Giller K., Huebbe P., Rimbach G. (2013). Nutrition and healthy ageing: calorie restriction or polyphenol rich 'Mediterr Asian' diet? Oxidative Medicine and Cellular Longevity. 2013:14.

41) Pant $S$ and Rinchen T. (2012). Dactylorhizahatagirea: A high value medicinal orchid. J. of Medicinal Plants Research. 6(19): 35223524. https://doi.org/10.5897/JMPR12.097 
42) Patel VR, Patel PR and Kajal SS. (2010). Antioxidant activity of some medicinal plants in western region of India. Adv. in Biological research. 4(1): 23-26.

43) Powers SK, Howley ET. (2001). Exercise Physiology: Theory and Application to fitness and Performance. $4^{\text {th }}$ ed. McGraw- Hill Highr Education 344-351.

44) Rad M, Sen DJ. (2013). Phytochemical and Antimicrobial Evaluation of the Essential Oils and Antioxidant Activity of Aqueous Extracts from Flower and Stem of Sinapis arvensis L. Am J Advan Drug Deliv. 1(1), 001-010. https://link.springer.com/article/10.1007/s13205 -014-0266-1

45) Rad JS, Alfatemi SH, Rad MS, Iriti M. (2013). Invitro antioxidant and antibacterial activities of Xanthium strumarium L. extracts on methicillin susceptible and methicillin resistant Staphylococcus aureus. Ancient Sci Life. 33: 109-13.

46) Rad M, Mohsenzadeh S, JAT da Silva. (2014). Chemical composition, antioxidant activity and In vitro antibacterial activity of Achillea wilhelmsii C. Koch essential oil on methicillin susceptible and methicillin resistant Staphylococcus aureus spp. Biotech. 1-6. https://www.ncbi.nlm.nih.gov/pmc/articles/PMC $\underline{4327754 /}$

47) Raja AF, Ali F, and Taneja SC (2011). Antistaphylo coccal and biofilm inhibitory activities of acetyl-11-keto- $\beta$-boswellic acid from Boswellia. BMC Microbiology.11: 54.

48) Rony MH, Imran MAS, and Sheikh MR. (2019). Determination of antimicrobial activity of medicinal plant $C$. obtusifolia L. (Chakunda) leaf extract on selected pathogenic microbes, Am. J. Pure Appl. Sci., 1(6), 59-69. https://doi.org/10.34104/ajpab.019.0195906

49) Rossmeisl M, Rim JS, Koza RA, Kozak LP. (2003). Variation in type 2 diabetes - related traits in mouse strains susceptible to dietinduced obesity. Diabetes. 52: 1958-1966.

50) Sarkar MHI, Uddin ME, Alam MF, Khatun MM. (2015). In vitro Micropropagation of Medicinal plant Abroma augusta L. (Ulat- kambal). Amer. Intern. J. of Res. in For., Appl. \& Nat. Sci., 1(12): 10-13.

http://iasir.net/AIJRFANSpapers/AIJRFANS15412.pdf

51) Sato A, et al. (2010). Anti-obesity Effect of Eicosapentaenoic Acid in High-fat/Highsucrose Diet-induced Obesity: Importance of Hepatic Lipogenesis. Diabetes.

52) Shahen MZ, Mahmud S, Uddin ME and Alam MS. (2019). Effect of antibiotic susceptibility and inhibitory activity for the control of growth and survival of microorganisms of extracts of Calendula officinalis, Eur. J. Med. Health Sci. 1(1), 1-9. https://doi.org/10.34104/ejmhs.0190109

53) Sharif IH, Haque MA, and Uddin ME. (2019). Assessment and biomoni-toring of the effect of rapeseeds oil on wister rat organs. Am. J. Pure Appl. Sci., 1(4), 20-29. https://doi.org/10.34104/ajpab.019.0192029

54) Sharifi Rad J, Sharifi Rad M, Iriti M. (2014). Free Radical Scavenging and Antioxidant Activities of Different Parts of $N$. schoberi L. TBAP, 4(1): $44-51$.

55) Sharifi-Rad J, Sharifi- Rad M, Setzer WN. (2014). Chemical Com-position, Antifungal and Antibacterial Activities of Essential Oil from Lallemantia royleana (Benth. in Wall.) Benth. J Food Safety.

https://doi.org/10.1111/jfs.12139

56) Siddiqui MZ. Boswellia Serrata, (2011). A Potential Anti-inflammatory Agent: An Overview. Indian J Pharm Sci. 73(3): 255-261.

57) Singh S, Singh J and Qazi GN. (2007). Boswellic acids and glucosamine show synergistic effect in preclinical anti-inflammatory study in rats. Bioorg Med ChemLett. 17(13): 3706- 3711.

58) St-Pierre LS, Parker GH, Persinger MA. (2009). Insidious weight gain in prepubertal seized rats treated with an atypical neuroleptic: the role of food consumption, fluid consumption, and spontaneous ambulatory activity. Epilepsy Behav 14: 288-92. https://pubmed.ncbi.nlm.nih.gov/19110073/

59) Talukder S, Uddin MS, and Baral PK. (2020). Phytochemical screening and bioactivity dete- 
rmination of ethyl acetate and methanolic extracts of leaf and bark of the plant $N$. arbortristis, Eur. J. Med. Health Sci., 2(6), 145-151. https://doi.org/10.34104/ejmhs.020.0145015

60) Toshima S, Hasegawa A, Nagai R. (2000). Circulating oxidized low density lipoprotein levels. A biochemical risk marker for coronary heart disease. Arterioscler Thromb Vasc Biol 20: 2243-2247.

61) Uddin ME., Ahmad T., Ranjan N. (2016). Standardization and improving In vitro micropropagation of Night Jasmine (C. nocturnum L.). Plant Archives, 16(1): 279-284. http://www.plantarchives.org/PDF\%2016\%20$\% 201 / 279-284 \% 20$ (PA3-3214).pdf

62) Um SH, et al. (2004). Absence of S6K1 protects against age- and diet-induced obesity while enhancing insulin sensitivity. Nature. 431: 200-205.

63) Vondrakova D, Ostadal P, Kruger A. (2010) Immediate effect of intensive atorvastatin the- rapy on lipid parameters in patients with acute coronary syndrome. Lipids Health Dis 9: 71. https://lipidworld.biomedcentral.com/articles/10. $\underline{1186 / 1476-511 X-9-71}$

64) WHO, (2016). Model List of Essential Medicines (19 ${ }^{\text {th }}$ List)" (PDF). World Health Organization. April 2015. Retrieved 8 December 2016.

65) Wider B, Pittler MH, Ernst E. (2009). Artichoke leaf extract for treating hypercholesterolaemia. Cochrane Database Syst Rev CD003335. https://pubmed.ncbi.nlm.nih.gov/19821306/

66) Wisse BE, Kim F, Schwartz MW. (2007). Physiology. An integrative view of obesity. Science 318: 928-929.

67) Zhang D, et al. (2010). Resistance to high-fat diet-induced obesity and insulin resistance in mice with very long-chain acyl-CoA dehydrogenase deficiency. Cell Metab. 11: 402-411. https://pubmed.ncbi.nlm.nih.gov/20444420/

Citation: Rahamn MA, Ara S, Hossain MK, and Rahman B. (2021). Assessment and evaluation of the leaf extract of Begonia barbata to the reduction LDL-cholesterol in Carbamazepine induced obese rats. Am. J. Pure Appl. Sci., 3(1), 17-28. https://doi.org/10.34104/ajpab.021.017028 (9) 